\title{
Analysis and Improvement of Emergency Mechanism for Hazardous Chemicals Accidents in Qingyang City
}

\author{
Ning Sun, Ke Gai, Qingling Guo, Zhenhua Li, Zhanjun Chen \\ School of Energy Engineering, Longdong University, 745000, Qingyang, China
}

\begin{abstract}
In recent years, with the rapid development of the economy, the dangerous chemicals enterprises in Qingyang City have also expanded and developed rapidly. The development of hazardous chemicals enterprises is increasing, the factors of instability are increasing, and the frequency of accidents involving hazardous chemicals is also increasing. While hazardous chemicals companies bring benefits, they also bring a serious threat to human life, health and property security. As a city with more dangerous chemicals companies, Qingyang has many potential safety hazards. In order to cope with many pressures, the Qingyang Municipal Government is vigorously carrying out safety production inspection and emergency mechanism construction in the hazardous chemicals industry. This paper analyzes the problems and deficiencies in the emergency management mechanism of Qingyang City from the aspects of accident prevention and early warning, emergency response, emergency plan preparation and emergency drill, which are mainly reflected in the weak foundation of accident early warning, imperfect laws and regulations, and weak awareness of public participation in emergency management. Finally, through the analysis of the existing problems and deficiencies, the emergency mechanism of Qingyang dangerous chemicals accident is improved.
\end{abstract}

\section{Introduction}

With the rapid development of dangerous chemicals production industry in China, the further expansion of production scale, the remarkable improvement of varieties and output, all kinds of new chemical materials, new products, new technology to bring great convenience to people's life, at the same time, the safety accident rate is also increasing. At present, the present situation of chemical safety in dangerous chemical enterprises in our country is not optimistic, fire, explosion and poisoning asphyxiation accidents occur frequently, compared with other safety production accidents, dangerous chemical accidents are more likely to cause casualties, property losses and environmental pollution, and will cause disastrous consequences to enterprises and society.

This paper takes Qingyang City as a specific case, analyzes the problems and deficiencies in the emergency management mechanism of Qingyang City from the aspects of accident prevention and early warning, emergency response, emergency plan preparation and emergency drill, and from the actual situation of Qingyang City, improves the emergency rescue mechanism to control and reduce the accident risk to the greatest extent.

\section{The main problems and shortcomings of the emergency mechanism of dangerous chemicals accidents in Qingyang City}

\subsection{Weak basis for accident warning}

The prevention and early warning mechanism of dangerous chemical accidents is the primary link of emergency mechanism, whether it can respond quickly, control the development of accidents in time, and curb the occurrence of production accidents, lies in whether the first line of dangerous chemical enterprises can find the hidden danger of production safety or unexpected situation in time. However, the early warning mechanism of accidents of dangerous chemicals enterprises lags behind in the enterprise, and some enterprises lack security education.

\section{2 emergency coordination and response mechanism to be improved}

In general, the emergency management agency of dangerous chemicals accident in Qingyang has set up a command center, and the supervision and control departments of dangerous chemicals have basically set up special emergency management agencies to deal with 
production accidents. However, there are some shortcomings:

(1) There is a gap in the level of information between departments, and the timeliness of information reporting needs to be strengthened.

(2) There are differences in public awareness among emergency response agencies.

(3) Because of the different degree of information between command agencies and technical factors such as different channels of information transmission and different data ports of command platforms, the information systems of various departments are independent of each other, fail to integrate organically and share resources in a timely manner.

\section{3 the public and other social organizations do not have strong awareness of participating in emergency management}

The government has the leading responsibility for production safety accidents, which does not mean that the public cannot participate in the response work. in the Emergency Response Law, citizens, legal persons and other organizations have the obligation to participate in the response to emergencies.

\section{Study on the Emergency Mechanism of Dangerous Chemicals Accidents in Qingyang City}

\section{1 emergency mechanism for hazardous chemical accidents}

The emergency mechanism refers to the emergency response mechanism for a social special event. It belongs to an emergency plan, which needs to be well prepared in advance. These precautions and strategies include not only material resources, but also human resources. The ultimate purpose of the emergency mechanism is to avoid further expansion or aggravation of the event, and to control the loss caused by the event as much as possible, Control the loss within the controllable range.

\section{2 analysis of prevention and early warning mechanism}

3.2.1 early warning level The accident grade and corresponding early warning response grade are shown in Table 1 below. Early warning information is timely adapted to the changing circumstances or events. When the accident is properly handled, timely reduce the warning level or directly announce the release of the warning.

Table 1 Warning and corresponding response levels for hazardous chemical accidents occurring or likely to occur

\begin{tabular}{|c|c|c|}
\hline Accidents and Early Warning Classification & Response level & remarks \\
\hline $\begin{array}{l}\text { Particularly serious accidents (Level I): More } \\
\text { than } 30 \text { deaths (including disappearances), or } \\
\text { more than } 100 \text { serious injuries, or a direct } \\
\text { economic loss of more than } 100 \text { million yuan in } \\
\text { particularly serious production safety incidents } \\
\text { Major accident (Level II); }\end{array}$ & $\begin{array}{c}\text { Particularly } \\
\text { serious I }\end{array}$ & $\begin{array}{c}\text { When level I emergency response needs } \\
\text { to be started, level II emergency } \\
\text { response shall be started for early } \\
\text { disposal }\end{array}$ \\
\hline $\begin{array}{l}\text { Causing more than } 10 \text { and less than } 30 \text { deaths } \\
\text { (including missing), or serious injury to more } \\
\text { than } 50 \text { and less than } 100 \text { people, or direct } \\
\text { economic loss of more than } 50 \text { million yuan and } \\
\text { less than } 100 \text { million yuan in production safety } \\
\text { accidents }\end{array}$ & Serious II & $\begin{array}{l}\text { Initiated by the provincial government. } \\
\text { When the district or city starts level III } \\
\text { response, the leading group will enter } \\
\text { the early warning state as the case may } \\
\text { be }\end{array}$ \\
\hline $\begin{array}{c}\text { Major accident (level III): } \\
\text { Production safety accidents causing more than } 3 \\
\text { and less than } 10 \text { deaths (including missing), or } \\
\text { serious injury of more than } 10 \text { and less than } 50 \\
\text { people, or direct economic loss of less than } 50 \\
\text { million yuan }\end{array}$ & More serious III & $\begin{array}{l}\text { Started by the city. When the county } \\
\text { (city, district) starts level IV response, } \\
\text { the city divided into districts enters the } \\
\text { early warning state. The leading group } \\
\text { and relevant regulatory departments } \\
\text { shall send working groups to the site to } \\
\text { guide the disposal work }\end{array}$ \\
\hline $\begin{array}{l}\text { General accident (level IV): } \\
\text { Accidents causing less than } 3 \text { deaths, or less than } \\
10 \text { serious injuries, or direct economic losses of } \\
\text { less than } 10 \text { million yuan }\end{array}$ & General IV & $\begin{array}{l}\text { initiated by the county (city, district) } \\
\text { government. Districts and } \\
\text { municipalities enter the state of early } \\
\text { warning, and send working groups to } \\
\text { the site to guide the disposal work. }\end{array}$ \\
\hline
\end{tabular}


3.2.2 release of early warning information The release of early warning information should be accurate, timely, objective and comprehensive, to prevent accidents to the maximum extent, to ensure the health of life and to maintain the safety of property. The early warning information shall include the issuing unit, the issuing time, the type of emergency that may occur, the scope of possible influence, the sub-warning level, the warning items, the relevant measures, the consultation telephone, etc.

\subsection{Analysis of emergency response mechanisms}

3.3.1 Response classification The basic tasks of accident emergency response are to control the hazard sources, rescue the victims, and eliminate the harmful consequences. The emergency response level of hazardous chemical accident is shown in Table 2.

Table 2 Emergency Response Level for Hazardous Chemicals Accidents

\begin{tabular}{cl}
\hline Level & \multicolumn{1}{c}{ Remarks } \\
\hline Level I & $\begin{array}{l}\text { The Emergency Rescue Committee of the State Council or provincial government shall } \\
\text { decide to start or terminate level I response } \\
\text { The provincial commanding organization or municipal leading group of chemical accidents } \\
\text { shall decide to start or terminate level II response }\end{array}$ \\
Level II & $\begin{array}{l}\text { The municipal level command organization of hazardous chemicals accident decides to } \\
\text { Level III } \\
\text { start or terminate level III response }\end{array}$ \\
Level IV & $\begin{array}{l}\text { The district (county) government decides to start or terminate level IV response } \\
\text { Level V }\end{array}$ \\
Decision to initiate or terminate Class V response by hazardous chemicals practitioners
\end{tabular}

3.3.2 response procedure According to the size and development trend of the accident, the emergency command, emergency action, resource allocation, emergency avoidance, emergency expansion and other response procedures shall be defined. The emergency rescue team shall enter the accident site in time, actively and rapidly carry out the emergency rescue work related to personnel rescue, engineering rescue, crowd evacuation, etc.

The leading group shall confirm that the production safety accident or danger situation has exceeded the emergency rescue capability of the department, and promptly request the local government departments and external rescue teams to carry out the emergency rescue work.

3.3.3 disposal measures According to the scale and possible consequences of production safety accidents, the following aspects shall be mainly dealt with after the accidents:

1. According to the accident category, carry out on-site disposal according to the disposal measures formulated in the special plan and on-site disposal plan;

2. For the accident type, accident hazard degree and other situations beyond the prediction of the emergency plan, organize professional technical personnel and relevant experts of work safety emergency rescue to formulate disposal measures according to the actual situation of the accident site, and then organize rescue to avoid blind rescue;

3. Evacuate the personnel at the scene of the accident in time according to the scope of influence of the accident. If it is necessary to evacuate the surrounding people, it is necessary to report to the relevant departments of the local government and cooperate with the evacuation of the people;

\section{Improvement of emergency response mechanism for hazardous chemicals accidents in Qingyang City}

\section{1 improve the early warning system of hazardous chemicals}

1. Improve the alarm and early warning system.

2. It is necessary to establish a hazardous chemical identification and early warning system, establish a special hazardous chemical research group or organization, integrate the major hazard source monitoring system, enterprise monitoring system, public security video monitoring system and fire early warning system, analyze and identify the dangerous points of hazardous chemical early warning, and propose emergency response measures.

3. Establish a government led safety publicity system, strengthen the daily training of the public's safety awareness and the popularization of self-help and mutual help knowledge.

\subsection{Construction of Emergency Disposal Platform for Hazardous Chemicals Accidents}

The construction of emergency response platform for hazardous chemicals is one of the key factors for rapid emergency response. Without an efficient and convenient emergency response platform, not only rapid and effective emergency response can not be achieved, but also empty talk. The emergency disposal of hazardous chemical accidents requires the departments to cooperate with each other, make scientific and unified decision and command, and realize the rescue joint efforts among relevant functional departments, so as to achieve the high 
efficiency of emergency response on the basis of resource sharing.

\section{3 improve emergency plan drill level and actual combat ability}

Emergency drill work should start from the following aspects:

(1) The scope of emergency drill should be expanded.

(2) The pertinence of emergency drill should be highlighted.

(3) Improve planning.

\section{Conclusion}

In order to improve the ability of emergency management of hazardous chemicals accidents, this paper analyzes the problems and deficiencies of the emergency management mechanism in qingyang city from the aspects of accident prevention and early warning, emergency response, emergency plan preparation and emergency drill. Finally, the emergency mechanism of hazardous chemicals accident in qingyang city is perfected by means of prevention and early warning mechanism, emergency response mechanism, information release mechanism, aftercare mechanism, emergency plan and drill.

\section{Acknowledgments}

This work was financially supported by department of industry and information technology of Gansu province (2019 Gansu province industry green low carbon transform topic-theoretical type 29).

\section{References}

1. Weidong Wang, Hui Shao. (2011) practice of hazardous chemicals safety production management and supervision.Sinopec Press, Beijing.

2. Yuye Sun, Dengyou Xia. (2008) emergency rescue and disposal of hazardous chemicals accidents. Chemical Industry Press,Beijing.

3. Haipeng Yin. (2004) study on emergency system management of hazardous chemicals accidents in industrial park. Tsinghua University Press,Beijing.

4. Hao Han. (2009) emergency management system for production safety in chemical areas in china. Renmin University Press,Beijing.

5. Xiankui Dai. (2015) Analysis on countermeasures for emergency disposal of chemical disasters. China Chemical Press, Lanzhou.

6. Zhenghong Zhao. (2012) Using information to promote the high efficiency of petrochemical emergency rescue. Journal of Harbin Engineering University, 32: 16-17

7. Jimei Cao, YaYou,Li Sun. (2015)Present situation and countermeasures of emergency drill in dangerous chemical enterprises. Safe, 2:21-24
8. Xiang Li. (2013) Problems and improvement of emergency response system for hazardous chemicals in china. Investment in technology in China, 16: 56-58 